\title{
ESCRITURA, MEMORIA Y DISCURSO: EL CASO DE RES GESTAE DIVI AUGUSTI*
}

\author{
WRITING, MEMORY AND DISCOURSE. \\ THE CASE OF RES GESTAE DIVI AUGUSTI
}

Nicolás Cruz

Pontificia Universidad Católica de Chile. Santiago, Chile ncruz@uc.cl

\begin{abstract}
Resumen: El presente artículo contiene una aproximación a la escritura a partir de la elaboración de la memoria y la correspondiente confección de un texto literario con la intención clara de incidir en la evaluación presente y futura de la obra política realizada por su autor. El caso de estudio específico es la inscripción Res Gestae redactada por el emperador romano Augusto hace dos mil años. La idea central expone que el interés de la inscripción radica en su condición de última elaboración de la memoria de los hechos consignados, más que en los criterios de veracidad-falsedad con que habitualmente ha sido abordado este escrito.
\end{abstract}

Palabras clave: Escritura, memoria, discurso, Augusto emperador romano, posteridad.

\begin{abstract}
This article contains an approximation to writing beginning with the elaboration of memory and the corresponding production of a literary text that has the clear intention of influencing in the present and future evaluation of the political work written by the author. The specific case study is the inscription Res Gestae, written by the Roman emperor Augustus two thousand years ago. The main idea sets forth that the interest in the inscription lies in it being the last elaboration of the memory of the events therein consigned and not in the criteria of truth-falsehood which is how this writing has usually been approached.
\end{abstract}

Keywords: Writing, memory, discourse, Augustus, Roman Emperor, posterity.

Recibido: 06.08.2014. Aceptado: 30.03.2015.

El presente artículo forma parte de las conclusiones alcanzadas en el Proyecto Fondecyt $\mathrm{N}^{\mathrm{o}} 1120036$ "La Construcción de la Memoria en los Inicios de la Roma Imperial". 
"Augusto reescribe todo" AlESSANDro BARCHIESI

$\mathrm{E}$ L EMPERADOR Romano Augusto (63 a.C. - 14 d.C.) redactó unas breves memorias políticas hacia el final de su vida, y dejó una indicación para que, a su muerte, fueran inscritas en dos columnas de bronce al ingreso de su monumental mausoleo en la ciudad de Roma. Tal cosa sucedió el año 14 d.C., y dado el título que agregó el editor a modo de encabezado, se le conoce como De las obras del divino Augusto, con las cuales sometió todas las tierras del orbe al Imperio romano, y de los gastos que hizo en favor de la República y el Pueblo romano ${ }^{1}$ (Zanker, 1990, p. 102). Su nombre abreviado, Res Gestae Divi Augusti (De las cosas hechas por el Divino Augusto), es con el que se le conoce de manera habitual.

El presente artículo contiene un estudio de la inscripción desde el punto de vista de la formulación de un discurso cuyo autor incidió de manera directa en la vida política romana durante 58 años. Los contenidos del mencionado texto estuvieron orientados a dejar en claro que él había restaurado el orden en el Estado y sentado las bases del régimen que había instaurado para este efecto, y que en ese proceso su voluntad política había resultado decisiva: él fue el hombre correcto en el momento adecuado, superando a algunas de las figuras anteriores más destacadas de la historia de Roma ${ }^{2}$. No resulta fácil identificar con claridad el público objetivo al que se dirigía Augusto, aunque resulta posible identificar a la clase política romana, a los jóvenes integrantes de la familia imperial en cuanto potenciales futuros encargados del gobierno, y también a los dirigentes de las ciudades provinciales que visitaban con frecuencia la capital del Imperio y que, muy probablemente, incluían el mausoleo de Augusto dentro de su recorrido. Un auditorio más amplio y difuso es aquel de las futuras generaciones de romanos, rasgo que se puede advertir a partir de la marcada intención de establecer una memoria sobre lo ocurrido una vez que él puso término a las guerras civiles.

${ }^{1}$ Res Gestae Divi Augusti quibus orbem terrarum imperio populi Romani subiecit, et impensae quas in em publicam populumque Romanun fecit.

${ }^{2}$ En relación a las figuras anteriores corresponde mencionar la medición que cada uno de los grandes líderes romanos hizo con la figura de Alejandro Magno. A este respecto, ver Cresci Marrone (1993), cap. 1. Para Augusto la figura inmediata a superar era la de Pompeyo Magno, y con una cierta ambigüedad a la de Julio César. 
Res Gestae es una inscripción breve si tenemos en cuenta el extenso tiempo abordado que se extiende desde el asesinato de Julio César hasta el año 12 d.C. en que concluyó su redacción ${ }^{3}$. De una manera sintética, claramente selectiva y utilizando un tono marcadamente personal, se inicia con su irrupción en la vida política luego de la muerte de Julio César el año 44 a.C., de quien era sobrino y heredero, así como el temprano apoyo que obtuvo de parte del Senado romano (párrafos I a IV); los poderes que aceptó para gobernar (V); los reconocimientos del Senado por la paz lograda y como estos se extendieron a los miembros de su familia (IX a XIV); los gastos realizados por él en favor de Roma (XV a XVIII,1); su actividad edilicia en Roma (XIX a XXI); los juegos ofrecidos al pueblo romano (XXII a XXIV); los juramentos realizados a su nombre luego de la batalla de Accio (XXIV); el crecimiento del Imperio romano, la instalación de colonias de soldados en diversos lugares del imperio (XXV a XXX); una extensa sección dedicada al reconocimiento de su persona y de Roma más allá de los límites imperiales (XXX a XXXIII), y finalmente, un resumen de su obra y reconocimientos que contiene lo que la posteridad ha considerado los conceptos medulares de su obra (XXXIV). La escritura escueta y focalizada del mensaje, donde no resulta posible advertir distracciones o divagaciones de algún tipo, bien puede servir como un campo para la exploración de la sicología del autor.

La idea central sobre la cual se levanta el discurso es que su obra fue la de un restaurador de la república y no un revolucionario que instaurara una nueva forma de gobierno personalizado y autoritario, aunque hubiese podido hacerlo en caso de haberlo deseado, dado el poder real del que llegó a disponer y ciertas presiones sociales en ese sentido. Este agregado no escrito, por cierto, puede encontrarse como subtexto en varios pasajes. $\mathrm{Su}$ línea de demostración a este respecto radica en que volvió a dotar al Senado de sus poderes tradicionales, los que el cuerpo colegiado tradicional ejerció sin problemas. La máxima comprobación de esta realidad se encontraría, según el autor, en los múltiples reconocimientos que los senadores le brindaron y la disposición que demostraron, de forma reiterada, para participar en aquellos espacios donde ello fue posible. Algo similar puede

${ }^{3}$ Solo para efectos ilustrativos, cabe señalar que la extensión de Res Gestae alcanza unas 10 páginas en las formas actuales de impresión. 
agregarse respecto de su representación y cuidados de la plebe romana de la que se habría convertido en su representante de por vida.

Res Gestae se inicia y cierra con la expresión directa de esta idea. En la apertura destaca haber formado un ejército personal con el que devolvió la libertad a Roma "oprimida por el dominio de una facción" y haber sido honrado por el Senado por esta acción. Tendremos oportunidad de volver sobre esta afirmación más adelante. $Y$ hacia el final, remata con el pasaje más celebre y discutido de la inscripción:

XXXIV, 1: En mi sexto y séptimo consulado, luego de haber extinguido las guerras civiles, transferí el control de todas las cosas de la República, que había asumido por el consenso de todos, al libre arbitrio del Senado y del Pueblo romano

XXXIV, 2: En vista del mérito mío, fui por un senadoconsulto, llamado Augusto y la puerta de mi casa fue adornada con laureles, y en la entrada fue puesta una corona cívica. En la Curia Julia se puso un escudo de oro donde se lee que esto me lo ofrecía el Senado y el Pueblo romano en reconocimiento a mi valor, clemencia, justicia y piedad ${ }^{4}$.

Conviene reparar en algunos de los contenidos significativos de un pasaje que evidencia la voluntad de Augusto en cuanto autor y conductor del proceso. Una voluntad manifestada tempranamente ya que lo hizo en su sexto y séptimo consulado, esto es, en los años 28 y 27 a.C., cuatro años después de su triunfo decisivo en la batalla de Accio contra su oponente Marco Antonio. En ese momento, señala, transfirió el poder que había asumido por el consenso de todos generado tras el fin de las guerras civiles ${ }^{5}$. Un aspecto en el que conviene reparar es en el uso del verbo transferir (transfero) que quiere representar de manera clara que los poderes estaban en manos de Augusto y que desde allí, y de forma voluntaria, los transfirió al Senado y al Pueblo romano. No fue una devolución o la entrega de una comisión que hubiese asumido de manera temporal.

${ }^{4}$ La traducción de los pasajes me corresponde. La traducción completa se encuentra en www.historiaycultura.cl, sección Textos/Escritos de Historia. La traducción fue revisada por el filólogo Antonio Arbea Gavilán, a quien agradezco infinitamente sus observaciones y precisiones.

${ }^{5}$ Una interesante relación entre el sentido de este pasaje y las intenciones del autor se encuentra en el comentario de Cooley (2009, p. 257). 
Esta idea de una restauración remata con la aseveración de que a partir del año 27 a.C. no tuvo poderes mayores a los de sus colegas en cada una de las magistraturas que desempeñó, aunque habría gozado de auctoritas, una suerte de poder simbólico difícil de precisar, generado por el reconocimiento de las distintas partes de la vida social y política romana. La situación, descrita en términos romanos, se describe en una disminución voluntaria de la potestas y una incidencia a través de una mantenida y creciente auctoritas, sostenida por la existencia de un consenso social respecto de la necesidad de contar con una suerte de princeps del Senado, potenciado en cuanto a su influencia en cada una de las esferas de gobierno.

Si el acuerdo con el Senado - con una presencia nada despreciable de integrantes nuevos provenientes del régimen-, y a través de él con los restos de la antigua clase dirigente romana, podía plantearse en términos de relativa claridad, no sucedía igual cosa con aquella que estableció con la plebe romana, un grupo de ciudadanos que habían tenido una gravitante participación política durante los últimos dos siglos del período republicano, y a los que la opinión pública moderada sindicaba como gestores de la crisis política inmanejable generada hasta el asesinato de Julio César el año 44 a.C.

Augusto en $R G D A$ menciona en varias ocasiones haber recibido la tribunicia potestad y haberse convertido, por esta vía, en el máximo representante de la plebe. Se trataba de un cargo que le permitía tener los poderes de los antiguos tribunos, pero sin deber ejercer las actividades cotidianas que habían caracterizado el ejercicio del cargo. Su nominación habría sido de carácter vitalicio y habría terminado por servir como forma de datación a los años de su gobierno. Poco y nada dice sobre la manera en que llegó a recibirlo y cuáles fueron los alcances de su ejercicio.

La idea que desarrollaremos a continuación puede resumirse de la siguiente forma: al interior de la estructura discursiva del autor de Res Gestae, las menciones al cargo de tribuno se encuentran en relación con aquellas repetidas ocasiones en las que él rechazó asumir poderes que concentraran el poder en sus manos y empujaran a la instalación de un poder monárquico en Roma. La mayor parte de estas demandas provenían, siempre según el relato de Augusto, de sectores plebeyos que solicitaban la referida concentración cada vez que la ciudad se encontraba en una crisis. El rechazo sistemático de Augusto a este tipo de iniciativas, evidenciaría su 
condición de auténtico restaurador de la República en sus términos tradicionales, y más aún, de ser uno de sus últimos y más decididos defensores.

De acuerdo con lo sostenido, corresponde diferenciar entre las menciones directas que hace a la tribunicia potestad que detentó, de aquellas otras que, sin haberlas protagonizado en cuanto tribuno, apuntaron al cumplimiento del papel de gran guardián y protector de los plebeyos romanos ${ }^{6}$. Entre las primeras señala haberla recibido [el año 23 a.C.] de por vida (X, 1), y certifica haberla ejercido de manera ininterrumpida hasta el momento en que puso fin a la redacción de sus memorias (37 veces)7. Indica también que a partir de su propia iniciativa, solicitó cinco veces contar con un colega $^{8}$, cosa que obtuvo (VI, 2). En otras ocasiones trae a colación esta potestad para fechar diversas acciones emprendidas no necesariamente en su condición de tribuno.

Hay una mención directa que requiere una mayor detención por sus implicancias. Respecto del párrafo VI,2 señala que en el marco de sus reiterados rechazos a desarrollar magistraturas de una manera contraria a 'las costumbres de nuestros antepasados', realizó aquellos actos que le solicitó el Senado basado en la tribunicia potestad. El párrafo es enigmático ya que no se sabe cuáles fueron las solicitudes del Senado, pero fueran cuales fueran, las hizo dentro de las atribuciones que le confería el poder de origen popular. Una vez más refuerza el discurso de que su acción se enmarcó en las leyes que regían Roma, y en este caso, y utilizando el mismo expediente

\footnotetext{
${ }^{6}$ De manera habitual se relaciona el elevado número de juegos ofrecidos por Augusto durante su gobierno con su política dirigida a la plebe. La animación del espacio público habría sido asumida por el régimen como una manera de compensar la pérdida de su gravitación política de los plebeyos. Sin descartar este argumento, cabe señalar que sirvió también para otros fines como el de la exaltación de las figuras de la familia imperial. El elenco de los juegos ofrecidos se encuentra en RGDA. XXII y XXIII.

${ }^{7} R G D A I V$, 4. Desde el año 36 a.C. Augusto ya contaba con la sacro santidad propia de los tribunos de la plebe. No obstante la discusión generada por la disparidad de las noticias en las fuentes, hoy tiende a aceptarse que la tribunicia potestad, propiamente, la recibió el año 23 a.C. A este respecto, véase Scheid, (2007, p. 44) "Comentarios".

${ }^{8}$ Las cinco veces en que solicitó un colega recayeron solo sobre Agripa y Tiberio, dos de sus más cercanos colaboradores y miembros asociados a su familia. Agripa recibió la Tribunicia Potestad el año 18 a.C. (por cinco años) y el año 13 a.C., por otros cinco años, pero su muerte al año siguiente caducó la designación. Tiberio lo fue en tres ocasiones: 6 a.C. (por cinco años); 4 d.C. (por diez años) y el año 13 d.C., esto es, un año antes de la muerte de Augusto.
} 
con que se refirió a su relación con el Senado, su voluntad habría sido manifiesta en contravenir lo que era el clamor popular por un mayor control de la ciudad.

Tanto su relación con los senadores como con los plebeyos, con el Senado como con las Asambleas Populares y sus representantes, por decirlo de manera más institucional, fue desarrollada, según Augusto, dentro del marco establecido. Parece conveniente reiterar el punto ya que los analistas han prestado más atención al funcionamiento de este mecanismo en el caso del Senado, que al relacionado con los plebeyos, asunto que parece muy necesario de profundizar.

Cada uno de los puntos argumentados hasta aquí por Augusto en la construcción de su imagen y la formulación de un discurso correspondiente han sido ampliamente discutidos por los historiadores que han investigado el tema, señalando que el Senado fue controlado progresivamente por el Emperador, quien fue incorporando a los suyos a los escaños, asegurándose lealtades y ejerciendo un fuerte control de la vida política por esta vía indirecta. Lo señalado parece ser correcto, ya que hacia el año 23 a.C., o quizás muy poco después, los focos de oposición dentro del organismo más antiguo de Roma se fueron mitigando, si no extinguiendo casi totalmente. Su ejercicio del tribunado de la plebe, por la otra parte, habría sido una fórmula utilizada por Augusto para potenciar su poder ante un Senado que se mostraba agresivo en los primeros años, hasta el 23 a.C., específicamente, y no contendría elementos de auténtica preocupación por los poderes políticos tradicionales de los plebeyos.

Hasta aquí hemos destacado dos de los elementos centrales del discurso de Augusto respectos de sus acciones (gestae). Este punto nos pone ante el problema de la(s) lectura(s) de Res Gestae Divi Augusti. La mayor parte de los trabajos de los historiadores se han dirigido a revisar y cuestionar los contenidos expuestos por su autor, destacando sus coherencias o incoherencias 9 . Sin subvalorar en absoluto la utilidad de estos ejercicios, cabe señalar que la inscripción nos pone frente a la última elaboración de la memoria realizada por Augusto en referencia a sucesos que empezaron

${ }^{9}$ Res Gestae ha sido objeto de varias ediciones y conviene atender a la historia del establecimiento del texto que entrega interesantes noticias. En cuanto a las ediciones con análisis de sus pasajes y una visión general de los temas planteados en ella, de- 
a desarrollarse cincuenta y seis años antes de ser puestos por escrito. Los estudios más recientes provenientes de distintos ámbitos en relación a las formas de funcionamiento de la memoria, indican que ésta reelabora los recuerdos en función de un presente lleno de intenciones, y que no lo hace acudiendo a una suerte de 'disco duro' en que se encuentren los hechos tal cual sucedieron en un determinado momento (Hustvedt, 2013).

Al momento de ingresar a la presentación del tema de los soldados y de las legiones dentro de Res Gestae, se puede presentar un ejemplo que permite profundizar de manera adecuada el punto recién mencionado. La inscripción se abre, tal como señalamos con anterioridad, con la siguiente afirmación: "A los diecinueve años alisté un ejército por decisión personal y financiado por mí con el cual devolví la libertad a la República oprimida por el dominio de una facción" (I.1) Digamos, antes que nada, que la sentencia reúne de un solo golpe los sucesos acaecidos entre los años 44

seamos destacar algunas de las ediciones publicadas a lo largo del siglo XX y primera década del siglo XXI. La primera edición comentada y texto de consulta obligado es la de Mommsen realizada entre los años 1865 y 1883, aunque los avances interpretativos y el hallazgo de nuevos fragmentos, acoten su consulta al valor de primera aproximación. Durante la primera mitad del siglo XX, dos interesantes ediciones estuvieron a cargo de las italianas Concepta Barini (1937) y Enrica Malcovati (1940). Durante el período de postguerra RGDA. fue objeto de poca atención, probablemente por la estrecha relación que se estableció entre la figura de Augusto y los regímenes totalitarios de Italia y Alemania, especialmente con el primero de ellos. Jean Gagé publicó en Belles Lettres una edición con escuetos y acertados comentarios en el año 1935. La misma casa editorial ha publicado en el año 2007 la excelente edición de John Scheid, la que contiene las varias copias transmitidas de la inscripción, sus traducciones al francés y un extenso apartado con los comentarios de gran erudición a cada uno de los pasajes. Especialmente valiosas son sus referencias a las fuentes. En 1967, P. A. Brunt y J.M. Moore publicaron una edición comentada que contiene una breve introducción, el texto latino y su traducción y un cuerpo de comentarios de mediana extensión. Esta edición gozó de mucha aceptación y fue consulta obligada por un largo tiempo. En Italia, en el año 1982, apareció luego de una larga sequía al respecto, una pequeña edición a cargo de Luca Canali con texto latino y traducción al italiano, acompañada de breves comentarios (ver bibliografía al final de este trabajo). $\mathrm{Su}$ aparición fue considerada muy significativa por la oportunidad más que por sus contenidos. Dos años después (1984) apareció mi traducción realizada del texto latino en la Revista de Historia Universal de la Universidad Católica de Chile, la que, hasta donde alcanzan mis conocimientos, sería la primera traducción a lengua española. Veinte años después, Juan Manuel Cortés publicó una muy completa e informada edición, traducción y comentario de Res Gestae Divi Augusti, recomendable desde todo punto de vista. Por último, y con un nivel similar a la mencionada de Scheid, apareció la magnífica edición de Alison Cooley (2009) que contiene, además, una completa puesta al día del estado de la cuestión. 
y 31 a.C., esto es, desde la muerte de Julio César y la consecuente decisión de Octaviano -después Augusto- de convertirse en el heredero político, y no solo económico, de Julio César, hasta la derrota de Marco Antonio -y Cleopatra- en la batalla de Accio, mencionados aquí como la 'facción'. El lenguaje utilizado es directo en extremo, de una evidente brevedad y de un marcado autoritarismo. Estaba, además, en plena concordancia con lo que había sido la versión oficial de los hechos difundida constantemente por la publicidad del régimen. Un análisis histórico detallado puede dejar en evidencia que el joven Octaviano actuó en la ilegalidad en un primer momento al sobornar dos legiones de las tropas del cónsul Antonio; que contó con el financiamiento de algunos cercanos a César; que Cicerón fue el senador que lo acercó a las esferas del poder curial, etc., pero todo eso, y mucho más: el nombre de sus enemigos, por ejemplo, queda silenciado frente a la manera en que él presentará los hechos y el de sus colaboradores más cercanos es traído a colación solo a partir de acciones protagonizadas por él o realizadas bajo sus órdenes.

Es posible sostener que el aspecto más novedoso y donde mayormente Augusto asentó el tono personalista de la memoria que fijó en la inscripción, fue en el ámbito militar y el de las victorias logradas. El Emperador controlará la totalidad de las legiones mediante mandatos especiales, reforzados en el tiempo por la condición de benefactor de los soldados y regulador de las actividades legionarias. Tácito, en una mirada retrospectiva, así como también Veleyo Patérculo, coincidirán que fue este el principal fundamento de la nueva forma de poder instalada en Roma.

En este campo, Augusto hizo cuatro afirmaciones centrales: haber traído la paz a una Roma convulsionada durante un largo tiempo por las guerras civiles; haber reordenado a las legiones mediante la reducción del número total de efectivos disponibles en el Imperio; haber puesto en acto un agresivo y sostenido proyecto de conquistas y, por último, haber generado un sistema de asignaciones económicas otorgadas por el Estado -jubilación diríamos hoy día- que beneficiaría a los soldados de su tiempo así como también a quienes desempeñasen esta actividad en el futuro. El resultado fue la paz estable dentro de las fronteras y la centralidad del mando militar que se había diluido en manos de los comandantes durante el último tiempo.

La llegada de la paz luego de su triunfo en las guerras civiles es un ar- 
gumento central que recorre la totalidad de la inscripción de Augusto, y se instalará como columna vertebral del discurso que ella contiene. En primer lugar, se trata de una paz en el vértice de un poder convulsionado por décadas y que tuvo como actores a aquellos comandantes que, recibiendo a través de distintos métodos, un encargo del Senado, se comportaban de manera autónoma en su carrera para manejar la ciudad y el Imperio. Este extenso capítulo es el que Augusto declara concluido con la derrota de Marco Antonio en Accio y que generó reconocimientos explícitos por parte del Senado. En un pasaje ya comentado con anterioridad (XXXIV, 1), relaciona la paz -en cuanto fin de 'las guerras civiles'- con la restauración de la República. La primera, entonces, sirve de fundamento y base a la segunda. Por este capítulo de la paz alcanzada Augusto recibió pleno reconocimiento por parte del Senado y del Pueblo Romano.

El establecimiento de una pax romana implicó también el control efectivo de las provincias y la derrota de los focos de resistencia que en ellas se encontraban. Esta labor, según se señala en la inscripción, fue una tarea prioritaria del gobierno y de Augusto, quien asumió esta tarea en términos personales o recurriendo a sus familiares más cercanos. En su texto, el emperador destaca dos reconocimientos explícitos a la paz lograda. El primero de ellos se encuentra en XII, 2 y se refiere a la construcción ordenada por el Senado de un Altar a la Paz Augusta (Ara Pacis Augusta) en el año 13 a.C. con motivo del retorno de sus viajes de pacificación en Occidente. El segundo, ubicado en Res Gestae inmediatamente después de la mención al Ara Pacis, señala que la paz alcanzada fue reconocida con tres cierres de las puertas de Jano - una frecuencia inédita en la larga historia de Romaubicadas en el noreste del Foro romano, muy cerca de la sede del Senado (Cooley, 2009, p. 157) y que, de manera simbólica, reconocían la ausencia de guerras dentro del Imperio.

El Ara Pacis terminó por convertirse en el monumento más representativo del vasto complejo de construcciones con claro significado político construido en tiempos de Augusto. Su conservación parcial, a diferencia de la mayor parte de los otros, ha asegurado la atención de todos los estudiosos del tema en el último tiempo. Conviene recordar que en el momento en que la inscripción de Augusto fue puesta en las dos columnas de bronce que servían de pórtico a su mausoleo, el Altar de la Paz había sido construido 
un par de décadas antes. La clausura de las puertas de Jano se ubicaba más en el campo simbólico, pero alcanzó mucha importancia en el programa publicitario del tiempo de Augusto sobre la pax romana.

En principio fue la paz, y la paz posibilitó la restauración de la República, rezaba el evangelio de Augusto. Y la mantención de la paz conllevó la ordenación del sistema militar romano y el cambio radical en la organización y vida de los soldados. El aspecto principal fue la reformalización real de la pirámide militar que remataría siempre en la figura del Emperador, único comandante en jefe de las legiones donde quiera que estuviesen estacionadas dentro del vasto territorio romano. Pero además, implicó el establecimiento de una carrera militar, remuneraciones conocidas por todos y la ya mencionada suma a la hora del retiro. Todo este proceso estaba dirigido y garantizado por el sistema central de gobierno: "Bajo el consulado de M. Lépido y L. Arruntio entregué ciento setenta millones de sestercios de mi patrimonio al erario militar que fue creado por mis consejos para dar los premios a los soldados que hubiesen militado veinte años o más” (XVII, 2). Por esta vía, la paz alcanzaba un mayor grado de profundidad y estabilidad al acercar a los soldados al régimen imperial y separarlo de las acciones y promesas de los comandantes a cargo de las legiones. Augusto, en cuanto escritor de la inscripción, expresa de forma reiterada y con detención, los beneficios entregados a los soldados desde los tiempos en que integró el triunvirato en los inicios de su carrera, y luego durante su gobierno en solitario. Esta preocupación, entonces, habría sido constante y fue posible gracias a una sostenida ingeniería política que permitió repartir tierras, pagar en dinero, establecer colonias y trasladar grupos de soldados desde un territorio a otro cuando llegaba el momento de premiar y reconocer los servicios prestados de acuerdo a los méritos de cada persona o grupo.

El tono personal que se advierte en Res Gestae, y al que hemos hecho varias referencias, encuentra su punto más alto y decidido cuando describe la nueva organización militar del Imperio. Ahí se lee que fue la obra de una persona que planificó y ejecutó la reforma y que para esto dispuso de fondos públicos y de su propio patrimonio para llevarla a cabo de una manera efectiva.

La pax romana fue un concepto utilizado por los romanos para indicar la ausencia de guerras interiores, pero no se refirió a la paz con respecto 
a los pueblos vecinos al Imperio, donde la solución de los conflictos por medio de las armas continuó siendo habitual. Y Augusto da buena cuenta de este punto que ha pasado a ser uno de los más controvertidos de su memoria. El punto radica en la supuesta convivencia de dos conceptos antagónicos: por una parte la serie de conquistas realizadas y el consiguiente crecimiento del Imperio de manera más que significativa (Crook, 1996, pp. 113-146), y por la otra, las menciones en fuentes tardías según las cuales Augusto habría aconsejado a Tiberio, ya designado sucesor, la conveniencia de detener el crecimiento del Imperio romano y centrar sus energías en la administración de lo dominado. El punto interesante, tal como ha señalado Alison Cooley, es que el supuesto consejo a Tiberio habría sido dado en una fecha muy cercana a la redacción de Res Gestae, donde se habría autopresentado como un conquistador de varias nuevas tierras.

En el caso de las legiones, y de manera más amplia en el del sistema militar romano reformado luego de las guerras civiles, la ordenación aparece definida de manera vertical, esto es, desde arriba hacia abajo. Las legiones fueron ubicadas en las provincias más conflictivas del Imperio desde el punto de vista militar, lo cual significó estacionarlas en las proximidades de las fronteras o en los límites mismos del Imperio, nutrirlas de manera progresiva, en un plazo mediano de tiempo, de naturales de esos mismos lugares e inyectarles una cantidad significativa de recursos que permitieran su funcionamiento y la satisfacción de los soldados desde el punto de vista de las rentas percibidas. Las fortalezas y debilidades del sistema fueron descritas de forma crítica por Tácito en varios pasajes de Anales, mientras que en Veleyo Patérculo, un soldado historiador, destacó sus aciertos en la segunda parte de su Historia de Roma.

Roma explicada desde dentro aparece como una república restaurada por la decisión inclaudicable de su princeps, siempre de acuerdo al discurso de Res Gestae, y que alimentaba a todo un extenso programa publicitario expresado a través de múltiples maneras. Desde fuera, su solidez y poderío la haría ser reconocida más allá de sus fronteras y la convirtió en una primera potencia que ordenaba la marcha del mundo conocido. Los últimos párrafos están destinados a resaltar las intervenciones solicitadas por reyes y reinos no incluidos en el imperio con el fin de asegurar transiciones monárquicas tranquilas, dar a hijos de reyes una educación romana a través de una estadía en Roma Caput Mundi, desarrollos de acuerdos comerciales, 
o simplemente, el establecimiento de relaciones con reinos tan distantes como la India, cosa que nunca antes había sido vista. La auctoritas de Augusto y el prestigio romano excedían los límites de sus dominios directos.

Hasta el momento nos hemos concentrado en el análisis del discurso de Augusto como una representación de su acción ante los entes (Senado, Plebe, Ejército, Provincias, etc.) y sectores sociales del Imperio romano, destacando el discurso de restauración que generó el autor de la inscripción. Pero, corresponde apuntar y destacar un contexto que nutre y cohesiona los distintos aspectos. En efecto, en el párrafo XXXIV, 2, citado al inicio de este texto, Augusto señala que el Senado, en uno de los reconocimientos más tempranos que el Senado hizo de sus obras y persona, dispuso que en su propio recinto se instalara un escudo de oro en que se destacaran sus cuatro virtudes: valor, clemencia, justicia y piedad ${ }^{10}$. De éstas, debidamente ilustradas en diversos pasajes de Res Gestae, proponemos percibir la piedad como aquella más específica y representativa de la imagen transmitida, y con mayor especificidad aún, de aquella piedad que mantenía y profundizaba la relación con los dioses protectores de Roma y su grandeza, asegurando poder y bienestar a su pueblo.

Entre los párrafos XIX y XXI, Augusto destaca sus intervenciones urbanas en Roma. Entre esas, menciona con detención las construcciones de templos y restauraciones llevadas a cabo, tanto aquellas mayores como la de "los ochenta y dos templos de los dioses en la ciudad, sin desatender ninguno que en ese tiempo exigiese arreglo" (RGDA XX, 4). Su intención fue la de destacar la orientación piadosa que tuvo una parte de su muy activa obra edilicia, esa que le permitió, según Suetonio, decir que había recibido una Roma de ladrillos y entregado una de mármol.

La piedad entre los romanos tenía un marcado componente retrospectivo, puesto que era en su historia donde se podía advertir con claridad que la grandeza lograda se había alcanzado en una íntima cercanía con los dioses, y que fueron los antiguos hombres piadosos quienes condujeron a Roma en las que consideraban sus grandes empresas, tanto en el plano de las conquistas como en la solución de los conflictos internos. Y Augusto, limi-

${ }^{10}$ A este respecto se encuentra una amplia descripción y explicación en Galinsky (2005 y 2012). 
taciones más o menos, había sido fiel a esa piedad, dándole el carácter conservador con que proponía a su tiempo y los siguientes, entender su obra.

Este mensaje estuvo presente en todo el discurso publicitario de Augusto, tanto en las construcciones, monedas acuñadas, así como en la literatura de la época y, dentro de esta última, lo encontramos como el eje de la Eneida de Virgilio, considerada como la obra emblemática del período. Eneas 'el piadoso' termina por ser un compendio de aquellas virtudes que luego los romanos desplegaran en el tiempo, y a las que Augusto adhirió, o señaló adherir.

\section{Referencias finales}

El sistema de gobierno, según deja ver el autor de Res Gestae, parece haberse establecido a partir de una suerte de programa que habría estado en la mente de su creador desde el principio. La historiografía dedicada al período, por su parte, ha tendido a describirlo no como un despliegue de algo previsto sino que como una lenta construcción en la que varios de sus aspectos centrales fueron alcanzados luego de ensayos, errores y logros, además de la intervención de factores externos que resultaron decisivos. Esta tensión es algo que no debe extrañar en un texto que se construye como una memoria ya que esta, en su última elaboración, tiende a establecer un orden y continuidad que se le otorga una vez que se observa el proceso ya cumplido.

Se obtiene bastante provecho cuando se lee la inscripción a través de los discursos que se pronuncian con decisión y en tono firme, pero también cuando se agregan al análisis sus significativos silencios. Entre estos últimos hay varios, tales como el hecho de que ninguno de los contrarios a Augusto aparece mencionado por su nombre, siendo el caso de Marco Antonio el más advertible, pero también se ha destacado que sus grandes colaboradores recibieron menciones escuetas. Pero el silencio más grande resulta ser el asunto de la cuestión sucesoria, una obsesión que rondó en la mente del emperador romano desde los primero años de su gobierno.

En efecto, el establecimiento de un régimen dinástico resultaba totalmente incompatible con una ambigua pero firme tradición romana y, por cierto, con el mensaje de la República restaurada. La tradición indicaba 
que un padre senador y aristócrata, por ejemplo, no heredaba sus cargos a sus hijos de manera directa y que estos debían hacer su propia carrera de los honores (cursus honorum), aunque por cierto que ellos corrían con un buen bastón de posta para llegar a la meta. Lo mismo podía decirse de los funcionarios plebeyos. La introducción del elemento dinástico era ajeno a la política romana y podía ser suficiente como para considerar el régimen como una construcción radicalmente nueva y monárquica. De ahí que no se encuentren referencias directas o indirectas a este punto, y las menciones de Agripa, Cayo y Lucio César -hijos del primero y de Julia, la hija de Augusto- y finalmente de Tiberio, apunten a otros asuntos y eludan el tema. Lo que nosotros podemos establecer con certeza es que la idea de la sucesión estuvo presente casi siempre en el diseño político del sistema. Este tipo de ambigüedades son las que hicieron que el analista mejor considerado de los aspectos constitucionales del poder de Augusto, haya terminado por señalar que “... utilizó un cierto conservadurismo del vocabulario constitucional: una tendencia natural que Augusto utilizó para disimular de mejor manera la importancia de las innovaciones introducidas en relación a la res pública antigua" (Ferrary, 2001, p. 116).

Con su memoria, discursos y silencios, la visión que Augusto entregó de su obra en la inscripción tuvo, y en parte sigue teniendo hasta nuestros días, aceptación. Incluso aquella línea de interpretación más crítica abierta por Ronald Syme en el año 1938, y que ha tenido muchos seguidores, reconocen que el extenso gobierno de Augusto logró éxito en sus objetivos, sirviendo para establecer un sistema cuyas bases se mantuvieron por un largo tiempo. En su último gesto autoritario el viejo gobernante tuvo éxito.

\section{Referencias}

Barini, C. (1937). Res Gestae Divi Augusti. Ex Monumentis Ancyrano Antiocheno Apolloniensi Concepta Barini. Roma: Scriptores Graeci et Latini. Consiglio R. Academiae Lynceorum.

Brunt, P. A. \& Moore, J. M. (1967). Res Gestae Divi Augusti. The Achievements Of The Divine Augustus. New York: Oxford University Press.

Canali, L. (1982). Cesare Ottaviano Augusto. Res Gestae Divi Augusti. Roma: Editori Reuniti.

Cooley, A. (2009). Res Gestae Divi Augusti, Text, Translation and Commentary. New York: Cambridge University Press. 
Cortés, J. M. (1994). Res Gestae Divi Augusti. Edición, traducción y comentario. Madrid: Ediciones Clásicas.

Cresci Marrone, G. (1993) Ecumene Augustea: una buona politica per il consenso. Roma: L’Erma di Bretschneider.

Crook, J. A. (1953). Some Remarks on the Augustan Constitution. The Classical Review, 3(1), 10-12.

. (1996). Augustus Power, Authority and Achievement. En A.K. Bowman,

E. Champlin \& A. Lintoot, The Cambridge Ancient History, vol. X "The Augustan Empire, 43 B.C. - A.D.69”, pp. 113-146, Cambridge: Cambridge University Press.

Ferrary, J.-L. (2001). À Propos des Pouvoirs D’Auguste. Cahiers Glotz, XII, 101-154.

Galinsky, K. (2005). The Cambridge Companion to the Age of Augustus. New York: Cambridge University Press.

. (2012). Augustus, Introduction to the Life of an Emperor. New York: Cambridge University Press.

Hustvedt, S. (2013). Vivir, pensar, mirar. Barcelona: Anagrama.

Malcovati, H. (1934). Res Gestae Divi Augusti. Enrica Malcovati. Roma: Edizioni Roma

. (1940) Imperatoris Caesaris Augusti. Operum Fragmenta. Henrica Malcovati. Torino: Quartum Edidít. Corpus Scriptorum Latinorum Paravianum.

Pani, M. (2013). Augusto e Il Principato. Bologna: Il Mulino.

Scheid, J. (2007). Res Gestae Divi Augusti. Hauts faits du Divin Auguste. París: Belles Lettres.

Syme, R. (1963). The Roman Revolution. Oxford: Oxford University Press. . (1989). Augustan Aristocracy. Great Britain: Clarendon Press.

Zanker, P. (1990). The Power of Images in the Age of Augustus. Ann Arbor: The University of Michigan Press. 